\title{
RADIAL VARIATION IN MICROFIBRIL ANGLE OF SUPER AND COMMON TEAK WOOD
}

\author{
Krisdianto $^{1}$
}

\begin{abstract}
Teak wood (Tectona grandis L.f.) is a well known and relatively slow growing hardwood species and popularly used as furniture and construction timber. Recently fast growing teak has been introduced which is named as super teak, as opposed to the existing common teak. The quality of super teak however, is being questioned and suspected to be not as good as common teak. Microfibril angle is one parameter of timber quality. It represents the angle between microfibrils and wood fiber axis when they are incorporated in a helical fashion to form fiber structure. The angle was measured from the orientation of long axis of elongated pits fiber. The mean angle of common teak was $22.05^{\circ}$, which is narrower than that of super teak of the same age, which was about $23.29^{\circ}$. Genetic factor is suspected to be the source for angle differences. In relation to wood stability during drying, it was predicted that common teak timber was more stable than that of super teak timber in the same age. In radial direction, the mean angle of both super and common teak declined from inner to intermediate and outer wood. The tendency for microfibril angles to be higher in the center of the log has some important implications for wood processing and tree improvement.
\end{abstract}

Keywords: Wood quality, wood stability, fiber, tree improvement

\section{INTRODUCTION}

Teak (Tectona grandis L.f.) is a popular tropical hardwood species belonging to the family of Verbenaceae. Teak timber is easy to process and suitable for constructions due to its second class strength and first to second class natural durability (Seng, 1964). It is used for outdoor and indoor furniture, boat decks and other purposes where weather resistance is desired. In addition, it is also very resistant to the attack of termites. In the past, when teak was plenty, teak was used extensively in Asian countries such as Indonesia, Thailand, The Philippine and India for doors and window frames, furniture and columns as well as beams. Nowadays, upper quality teak timber (produced from mature trees) fetches a very good price, limiting its uses only for the high-end products.

Teak trees that are grown conventionally from seedling grows slowly with a rotation up to 45 to 60 years. Recently, a faster growing teak which is popularly

Forest Products Research and Development Center, Jl. Gunung Batu No. 5, Bogor 16610, Indonesia. E-mail: krisdianto@dephut.go.id 
labelled as 'super teak' was introduced. The plant material of this 'fast-growing' teak is produced using tissue culture technology. Super teak is claimed to grow 3 - 4 times more rapid than common teak (Bachri, 2001), hence shortening the rotation to merely 15-20 years. However, many suspect that teak timber from fast-growing or shorter-rotation trees is not as strong, durable and stable as that from old common long-rotation trees. It might be more prone to splitting and water damage.

As scientifically-based information about timber quality of super teak has not yet available, a research to obtain the information is necessary. One of parameters for measuring wood quality is the microfibril angle. Microfibril is the smallest component of cell wall structure about $3-4 \mathrm{~nm}$ in diameter and consisting of a group of cellulose molecules (protofibril) surrounded by a sheath of hemicellulose (Kerr and Goring, 1975 in Lima et al., 2004). The microfibril angle is defined as the angle that microfibrils make with the wood fiber axis when they are incorporated to form fiber structure (Stuart and Evans, 1995). Generally, the orientation of the microfibril in $S_{2}$ layer in angiosperms ranges about $5^{\circ}$ to $20^{\circ}$, whereas the comparable range for gymnosperms is from about $10^{\circ}$ to $30^{\circ}$ (Boyd, 1980).

The microfibril angle of the S2 layer represents an important ultramicroscopical feature influencing the performance of wood products. For example, the angle has a major effect on the stability of wood on drying and following subsequent manufacturing processes (Zobel and Buijtenen, 1989). Both the longitudinal tensile strength and stiffness of wood have been shown to be markedly affected by microfibril angle, as the angle increases so tensile strength and stiffness quickly decrease. Long cells, with low microfibril angles result in more stable and stronger boards. The incidence of high microfibril angle is one reason explaining juvenile wood of loblolly pine is weak and somewhat unstable (Pearson and Gilmore, 1980). Although other mechanical properties appear to be only slightly affected by microfibril angle (Desch and Dinwoodie, 1993) there does appear to be sufficient variation in microfibril angle between trees to justify selection of tree improvement (Cave and Walker, 1994).

Boyd (1977) reported that longitudinal shrinkage increases progressively as the fiber morphology changes from the mean representative of normal wood and approaches that of reaction wood, with the absence of a thick lignified S2 layer and large microfibril angle in the S1.

A number of methods used to estimate microfibril angle have been studied. A few authors have used pits aperture to estimate microfibril angle in softwood (Wellwood, 1962; Donaldson, 1993) as well as hardwood (Sturt and Evans, 1995, 1996). Stuart and Evans (1996) calibrated microfibril angle of Eucalyptus nitens measured from elongated cell wall and calibrated them using x-ray 
diffractions. There was a good linear correlations exists between pit angle and x-ray diffraction parameter for $E$. nitens.

The main objective of this work was to study the variation of microfibril angle in the S2 layer of the libriform fibers of 'super and common teak' of the same age obtained from in Penajam, East Kalimantan. The angles were measured from fiber pit aperture, as it is demonstrated by Stuart and Evans (1996).

\section{MATERIALS AND METHODS}

\section{A. Sampling Site}

The wood samples used in this study were collected from seven-years-old super and common teak plantations in Penajam, PT ITCI Kartika Utama, East Kalimantan. Discs were taken from each three trees of both super and common teaks. The discs were taken about 1.3 meter above the ground. In one tree, disc of about $5 \mathrm{~cm}$ thick was taken from the bottom, middle and top of the tree. In every disc, samples were taken from three locations, namely inner (near pith), intermediate and outer (near bark) part of the disc.

Both kind of teak trees were planted in the same site in August 1998. In general, the topography of the site is mostly hilly with less flatland area. The altitude of the side is about $80 \mathrm{~m}$ above sea level and the soil contains yellowreddish podsolic soil.

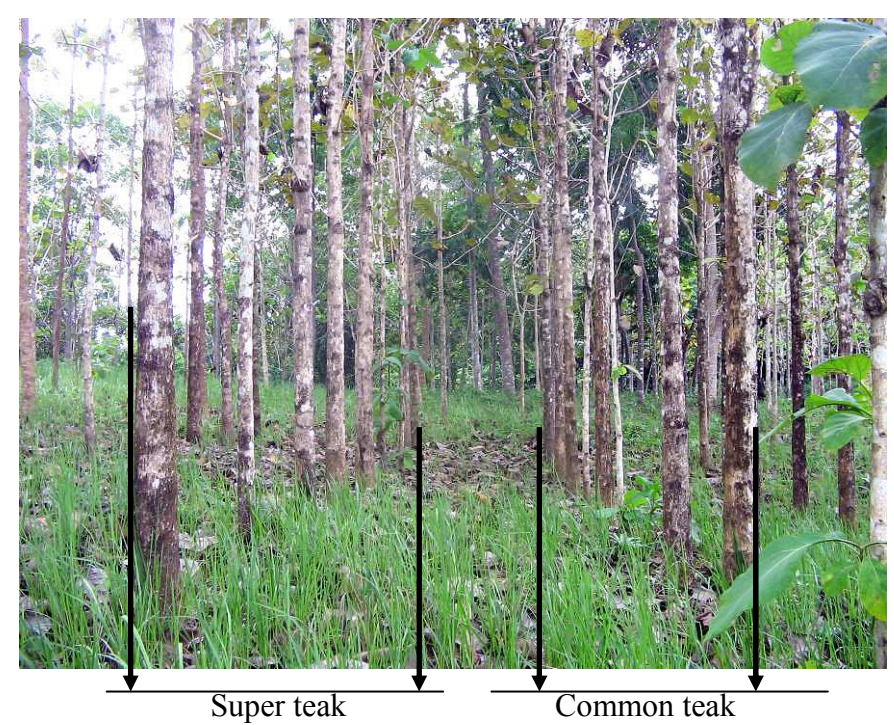

Figure 1. Super and common teak in the experimental site 


\section{B. Microfibril Measurement}

Microfibril angles were measured from macerated samples, a procedure of maceration was explained by Tesoro (1989). Teak wood picks in size of $2 \mathrm{~m}$ x $2 \mathrm{~mm}$ x $20 \mathrm{~mm}$ were heated slowly at $40-60^{\circ} \mathrm{C}$ in the mix of concentrated nitric acid and hydrogen peroxide in ratio of $1: 1$. The heating took about 12 hours to produce adequately macerated material on a satisfactorily separation of wood fibers.

Photos of selected pit were taken from single fiber using 20x objective lens of the conventional microscope. Pits very close to the outer edge of the fiber were omitted as their measured angle may be affected by the collapsed edge. The direction of the fiber axis at the position of the pit along the fiber was estimated by aligning the fiber axis with the ocular cross-hairs and recording a reading on the vernier. This was used as the reference direction. The stage was rotated until the long axis of the pit was aligned with the ocular cross-hairs and another vernier reading recorded. The difference between the two angles was calculated as the pit angle (Figure 2).

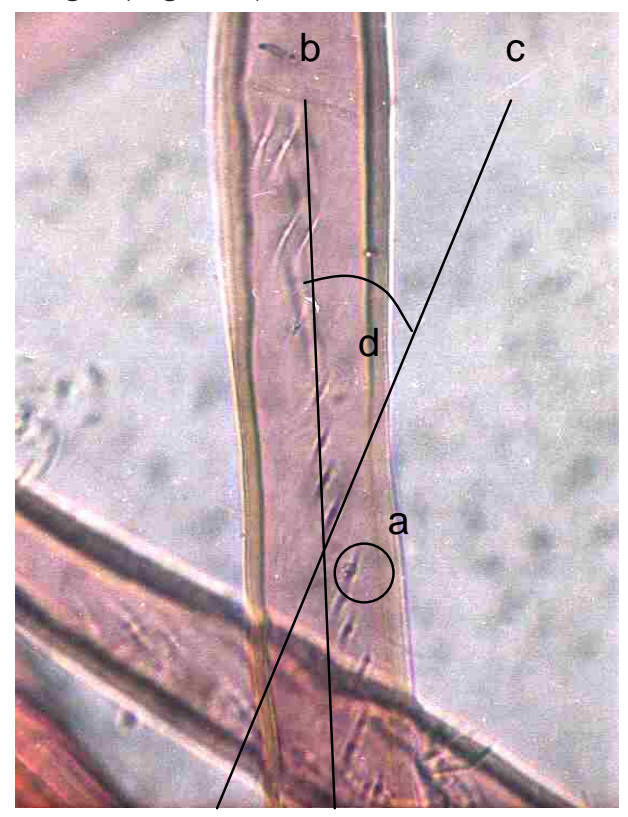

Figure 2. Single macerated teak fiber

Note: a: elongated pit; b: reference direction; c: long axis of pit; d: pit angle 


\section{Parameters and Variables Investigated}

Three parameters of teak microfibril angle were investigated: teak species, tree variation and radial depth. Teak species variables studied include super and common teak, while tree variation studied include first, second and third tree. Variable of radial depth includes inner, intermediate and outer sides. Thirty replicates were measured from macerated samples, using a total of 540 fibers measured.

\section{RESULTS AND DISCUSSION}

The microfibril angle measured in this study is the average angle within the complete cell wall, comprising primary and secondary wall with its S1, S2 and S3 layers, each having different predominant arrangements of microfibrils. As the S2 layer comprises the largest proportion of the wall, the measured angle is close to that in this layer. In this work, the angles were measured at the fiber mid point, although the angle changes along the length of the fiber (Lima et al., 2004). In conifers, a larger microfribril angle is observed in radial walls, where microfibrils form whorls around the bordered pits which are predominantly found here rather on tangential walls (Meylan, 1967). However, Stuart and Evans (1995) pointed out that for Eucalyptus, which is broad leaved, it is unlikely that pit apertures in fiber-tracheids would have a noticeable influence on the magnitude of the microfibril angle, since fiber-tracheids in the wood of this genus have smaller and far fewer pits and are only marginally more numerous on radial walls than on tangential walls. Even so, it should be noted that the method used here favoured measurement on the tangential face of the fiber.

Radial variation (inner, intermediate-wood and outer-wood) of microfibril angle of 7-years teak wood is shown in Table 1. 
Table 1. Radial variation of microfibril angle (degrees) of 7-years super and common teak wood

\begin{tabular}{lcccc}
\hline \multirow{2}{*}{ Species } & \multicolumn{4}{c}{ Radial position } \\
\cline { 2 - 5 } & Inner & Intermediate & Outer & Mean \\
\hline Super teak - 1 & 25.2 & 22.3 & 21.1 & $22.9 \pm 2.57$ \\
Super teak - & 26.1 & 22.7 & 21.5 & $23.5 \pm 2.64$ \\
Super teak - & 25.5 & 23.0 & 22.1 & $23.5 \pm 2.57$ \\
\hline Mean & 25.6 & 22.7 & 21.6 & \\
\hline Total mean & & & & $23.29 \pm 2.61$ \\
\hline Common teak - & 24.0 & 21.2 & 20.5 & $21.9 \pm 2.39$ \\
Common teak - & 25.2 & 21.0 & 19.5 & $21.9 \pm 2.89$ \\
Common teak - 3 & 25.5 & 22.0 & 19.5 & $22.3 \pm 3.01$ \\
\hline Mean & 24.9 & 21.4 & 19.8 & \\
\hline Total mean & & & & $22.05 \pm 2.78$ \\
\hline
\end{tabular}

Generally, the mean microfibril angle of common teak is lower than that of super teak. The angle mean of common teak is $22.05^{\circ}$, while that of super teak is $23.29^{\circ}$. The paired sample t-test between common and super teak showed that the angle of microfibril measured is significantly different. There are two factors that may induce microfibril angle, namely genetic and environment (Nakada et al., 1998). Genetic factors of super and common teak may strongly affect the angle differences, while environmental factors may be eliminated as teak tree samples were taken from the same site. Super teak plantation is mostly developed from plus-teak tree in certified seed orchard in Java, while common teak plantation is commonly developed from seeds that may not be necessarily produced by a plus-teak tree.

In relation to wood stability during drying, it is predicted that common teak timber is more stable than that of common teak timber on the same age. As common teak has narrower angle than common teak, both the longitudinal tensile strength and stiffness of super teak may be higher than super teak on the same age. This prediction is based on the fact that the lower the microfibril angles, the more stable and stronger the board is (Pearson and Gilmore, 1980).

In radial direction, the angle declines from inner to intermediate and outer wood. In super teak, the angle mean of inner discs are $25.6^{\circ}$ and it decreases to $22.7^{\circ}$ in intermediate wood and $21.6^{\circ}$ in outer wood. These represent an overall reduction from inner position to the outer of about $18.5 \%$ in super teak discs. This tendency also occurs on common teak; as the narrowest angle was found 
in outer part of the disc. The mean angle of the inner disc is $24.9^{\circ}$. The angles decrease by about $25.8 \%$ toward intermediate and outer discs $\left(21.4^{\circ}\right.$ and $19.8^{\circ}$ respectively). The results of the analysis of variance of the microfibril angle are shown in Table 2.

Table 2. Analysis of variance of microfibril angle of 7 years old super and common teak

\begin{tabular}{lrrrrr}
\hline \multicolumn{1}{c}{ Source } & df & Sum of Squares & Mean Square & \multicolumn{1}{c}{$\mathrm{F}$} & $\mathrm{P}$ \\
\hline Intercept & 1 & $277,489.869$ & $277,489.869$ & $80,653.787$ & $* *$ \\
Teak & 1 & 205.967 & 205.967 & 59.865 & $* *$ \\
Tree & 2 & 28.084 & 14.042 & 4.081 & $* *$ \\
Radial & 2 & $1,962.718$ & 981.359 & 285.237 & $*$ \\
teak * tree & 2 & 8.727 & 4.364 & 1.268 & ns \\
teak * radial & 2 & 24.983 & 12.492 & 3.631 & $*$ \\
tree * radial & 4 & 32.505 & 8.126 & 2.362 & ns \\
teak * tree * radial & 4 & 39.271 & 9.818 & 2.854 & $*$ \\
Error & 522 & $1,795.944$ & 3.441 & & \\
Total & 540 & $281,588.07$ & & & \\
\hline Rema & $\leq 0.01 ;$ & & & &
\end{tabular}

Remarks : $* \mathrm{P} \leq 0.05 ; * \mathrm{P}<0.01 ; \mathrm{ns}=$ not significant $(\mathrm{P}>0.05)$

As shown in Table 2, there are significant differences in microfibril angle between super and common teak as well as between tree samples $(P \leq 0.01)$. In radial position, there is also significant differences between inner, intermediate and outer position $(\mathrm{P} \geq 0.05)$. While, the interactions between teak and sample trees as well as radial position and tree is not strongly significant.

The systematic tendency for decreasing microfibril angle from pith to bark was also identified by various authors. Most results reported are for conifers which grow relatively slow in temperate regions and have a large numbers of growth rings in commercial sized logs (Donaldson, 1992, 1993; Cave and Walker, 1994). However, a more detailed examination of the results of these researches shows that from one cambial age to the next (from pith to bark) the microfibril angle can decrease, stabilise or even increase depending on the species. The systematic patterns of microfibril angle in radial position of teak are similar to the work reported by Lima et al. (2004) on some Euclayptus species. Lima et al. (2004) reported that in radial pattern of some Eucalyptus species, the angles are larger in the inner and decrease toward periphery. 
The tendency for microfibril angles to be higher in the center of the log has some important implications for processing and tree improvement. Normally the central region of the log is a critical zone, since it consists of juvenile wood which has high percentage of shrinkage and swelling. Wider microfibril angle in the region of the juvenile wood (inner wood), significantly increased longitudinal shrinkage and distortion of kiln dried lumber cut from trees with a large juvenile core (Megraw, 1985). During sawing process, the central region should be avoided as it reduces the log quality. However, seven years old teak tree contains mostly juvenile wood as the stem is still in growing condition.

In term of tree improvement, the research efforts should be concentrated on reducing microfibril angle in the inner region. Since the inner wood at the base of the stem is the first formed in the tree, it is possible that selection of stock producing 'prime' material could be made early in the life of the trees.

\section{CONCLUSION}

1. The mean microfibril angle of common teak is narrower than that of super teak of the same age. In relation to wood stability during drying, it is predicted that common teak timber is more stable than that of super teak timber of the same age. As common teak has narrower angle than super teak, both the longitudinal tensile strength and stiffness of common teak may be higher than that of super teak of the same age.

2. Genetic factors are considered the strongest sources of microfibril angle differences between super and common teak.

3. In radial direction, the mean angle of super and common teak decline from inner toward intermediate and outer wood. The tendency for microfibril angles to be higher in the center of the log has some important implications for wood processing and tree improvement.

\section{REFFERENCES}

Bachri, S. 2001. Jati super andalan hari tua. WWW page: http://www/ mitrabisnis.com/1301/11301a.htm. Downloaded 5 November 2005.

Boyd, J.D. 1977. Relationship between fiber morphology and shrinkage of wood. Wood Science Technology 11: 3-22.

Boyd, J.D. 1980. Relationship between fiber morphology, growth strains and physical properties of wood. Australian Forest Research 10: 337-360.

Cave, I.D. and J.C.F. Walker. 1994. Stiffness of wood in fast-grown plantation softwoods: the influence of microfibril angle. Forest Products Journal 44: 43-48. 
Desch, H.E. and J.M. Dinwoodie. 1993. Timber, Its Nature and Behaviour. Van Nostrand Reinhold Co. Wokingham, UK. 190 pp.

Donaldson, L.A. 1993. Within and between tree variation in microfibril angle among three genetic groups of Pinus radiate trees. New Zealand Journal of Forestry Science 23: 90-100.

Lima, J.T., M.C. Breese and C.M. Cahalan. 2004. Variation in microfibril angle in Eucalyptus clone. Holzforschung 58: 160-166.

Megraw, R.A. 1985. Wood quality factors in Loblolly Pine, the influence of tree age, position in tree and cultural practice on wood specific gravity, fiber length and fibril angle. TAPPI Press, Atlanta.

Meylan, B.A. 1967. Measurement of microfibril angle by X-ray diffraction. Forest Products Journal 17: 51-58.

Nakada, R., Y. Fujisawa, D. Nishimura, and Y. Hirakawa. 1998. Variation in $\mathrm{S}_{2}$ microfibril angle of latewood among plus-tree clones and test stands in Cryptomeria japonica D.Don. In: B.G. Butterfield (Ed.). Workshop on the significance of Microfibril Angle to Wood Quality. IAWA/IUFRO. Leiden, Netherland. pp. 367-374.

Pearson, R.G. and R.C. Gilmore. 1980. Effect of fast growth rate on the mechanical properties of loblolly pine. Forest Products Journal 30: 47-54.

Preston, R.D. 1934. The organization of the cell wall of the conifer tracheid. Philosophical Transactions of the Royal Society. Series B 224: 131-174. London, UK.

Preston, R.D. 1974. The Physical Biology of Plant Cell Walls. Chapman and Hall, London. 491 pp.

Seng, O.D. 1964. Berat jenis dari jenis-jenis kayu Indonesia dan pengertian beratnya kayu untuk keperluan praktek. Pengumuman No.13. Puslitbang Hasil Hutan. Bogor.

Stuart, S. and R. Evans. 1995. X-ray diffraction estimation of the microfibril angle variation in eucalypt wood. Appita 48: 197-200.

Stuart, S. and R. Evans. 1996. X-ray diffraction from Eucalypt increment cores Part II: Calibration of microfibril angle measured from x-ray diffraction using optical microscopy and prediction of fiber length. Research report No. 92. The CRC for Hardwood Fiber and Paper Science, Melbourne.

Tesoro, F.O. 1989. Methodology for Project 8 on Corypha and Livistonia. FPRDI College, Laguna, Phillipines.

Wellwood, R.W. 1962. Tensile testing of small wood samples. Pulp and Paper Magazine of Canada 63: T61-T67. Pointe-Claire, Quebec, Canada. 
Journal of Forestry Research Vol. 5 No. 2, 2008: 125 - 134

Zobel, B.J. and J.P. Van Buijtenen. 1989. Wood-Variation - Its Causes and Control. Springer Verlag, Berlin. 363 pp. 